Journal of Contemporary Educational Research

Research Article

\title{
Analysis of the Application of the Flipped Classroom in the Teaching of College Education Courses
}

\author{
Xu Deng* \\ College of Physical Education, Henan University of Science and Technology, Luoyang, Henan Province, China
}

\begin{abstract}
The flipped classroom model is a method of educational reform that meets the needs of information technology development. On the one hand, it can promote the development of innovative and applicable human resources and improve the level of individual learning of university students. On the other hand, it can encourage the practice of teaching students using modern technologies and the need for teachers to master the use of the flipped classroom in higher education. Beginning with updating concepts and raising awareness, teachers need to change their learning habits and traditional teaching methods to facilitate the development of pedagogical reforms further. This paper introduces the concept and characteristics of the classroom. It proposes strategies for applying the flipped classroom, including organizing teaching activities, setting learning objectives, and micro-video design and production.
\end{abstract}

Keywords: Flipped classroom; Pedagogy; Curriculum teaching

Publication date: August, 2020

Publication online: 31 August, 2020

*Corresponding author: Xu Deng, 929999811@ qq.com

\section{Introduction}

Pedagogy is the primary specialization of the university education program, and the quality of education in the primary program directly affects the future development of students in the field of knowledge and their ability to teach. In the process of the traditional teaching model, the teacher is considered the centre of teaching. However, this type of teaching model is no longer able to meet the needs of the current social development for the growth of students. To cope with these problems, we have changed the traditional teaching model and are continually learning new scientific models of teaching. In the flipped classroom, which is the result of innovations in education and pedagogy, students must learn independently, be prepared, and have a basic understanding of the content before class ${ }^{[1]}$. The curriculum emphasizes teacher-student interaction and discussion, as well as the importance of communication and cross-referencing. However, the flipped classroom has relatively few applications for classroom use in teaching university courses. To remedy this shortcoming, this paper makes the following analysis.

\section{The concept and significance of flipped classroom applications}

\subsection{Concepts within the flipped classroom}

The flipped classroom is an instructional method created through innovation in traditional teaching methods, where students must have the ability to learn independently and have appropriate preparation and knowledge of the content before class. Teachers achieve effectiveness and quality of education by first instructing students to discuss actively and then interact with what they have learned and by identifying the core elements that enhance their learning. Students can take the initiative to acquire the knowledge beforehand, collect relevant reading material and use videos to go for a comprehensive understanding of the points that need to be learned ${ }^{[2]}$. At the same time, the teacher can use classroom instruction to provide students with opportunities for active learning by guiding them to analyze the knowledge points, thus emphasizing the students' subjective position. The teacher then instructs the students to actively participate in classroom practice so that they can better engage in learning and participate 
in incomplete teaching practice.

\subsection{The significance of the application of the flipped classroom}

(1) Developing Talent. Because much of the content of college courses is relatively conceptual, students studying in college courses often stay on the surface of concepts. In contrast, the teacher remains on the surface of information in descriptions rather than instructing students to think actively about the issues. If a flipped classroom is used in the college education process, not only can students deepen their understanding and appreciation of the focus of college education, but they can also deepen their knowledge of ideas and content by actively thinking about the integration of abstract subjects into their learning. In this way, students can increase their awareness of overall educational activities and can have a deeper understanding of the comprehensive, informative content ${ }^{[3]}$.

(2) Enhancement of learning effectiveness. In the process of using a flipped classroom, teachers can use various ways and methods to implement effective teaching process, and students can use appropriate learning methods to pre-reading the knowledge points. In practice, students are pre-reading the knowledge points before the lesson and making lists for points they do not understand. Based on this, they then make full use of the lecture time to communicate and interact with the teacher to analyze and discuss severe problems.

(3) Innovative teaching methods. With the rapid development of society and changing educational practices, the comprehensive understanding of educational goals in lifelong learning courses have been enhanced. However, in most universities, large-scale teaching is inefficient for education students due to difficulties in meeting and demand. The use of flipped classrooms can be used to gain sufficient efficiency in classroom learning. Also, a flipped classroom can enable many students to have a higher interest in education and improving themselves. Through the use of the flipped classroom, teachers can enhance their professionalism, be more scientific and efficient, and make classroom design have practical relevance.

(4) Build an efficient learning process. Applying flipped classrooms can provide a more active learning process. The traditional teaching methods in university education are no longer able to meet the growing needs of students due to the lack of guidance and support and the internalization of the content after the class. Therefore, it is necessary to change this mode of teaching in specific teaching practices. Teachers can enable the internalization and absorption of the entire teaching process once it is completed through online transmission, using the classroom hours to interact with the students and teachers in the classroom.

\section{Strategies for Using the Flipped Classroom in College Education Courses}

In traditional pedagogical teaching methods, student preparation is often neglected, classroom instruction is primarily explained by the teacher, and interactions between teacher and students tend to fall into meaningless routines. This makes the entire classroom lack energy. The application of the flipped classroom can stimulate student initiative and promote teacherstudent interaction. Its central teaching strategies are:

(1) Clarify the objectives. First of all, before creating the micro-lessons, the university pedagogues clarified the teaching objectives and human resources training requirements, selected the core and painful points, divided the content into different knowledge point groups, and determined the goals of each knowledge point group. And by analyzing the knowledge points to reconstruct the other knowledge points in the university pedagogical content, the institutional knowledge framework was clarified ${ }^{[4]}$. Among the general objectives is the development of an accurate and rational educational plan based on the educational needs and goals of university pedagogy. For scientific, instructional videos, the pedagogical purposes in the event of flipped classroom education at the university are divided into competency goals, assessment knowledge goals, emotional goals, etc. By setting scientific, educational purposes, it enhances the understanding and accumulation of pedagogical educational knowledge of university students. By developing a practical application of knowledge and skills, a good foundation is laid for improving students' general cultural literacy, as well as for follow-up and learning. Also, in the division of textbook chapters, it is necessary to clarify the main points of knowledge, record the contents of the textbook, fully explain the relevant concepts of the book, and encourage active learning by professors and students. The teacher needs to pay attention to the basic theory of pedagogy and develop students. The ability to apply knowledge skills and improve cultural literacy. And explain these in detail to help students learn independently and to lay a good foundation for future research and work.

(2) They are guiding students to learn independently. Before classroom training, students must study and analyze the mini-videos in advance, using a variety of web-based terminal devices. At this point, students must 
consider carefully, have a basic understanding of the educational content, pay attention to and understand and comprehend the course content. They will complete the tasks assigned in the video by analyzing the material for questions.

(3) Promote students' internalization of knowledge. Group discussions and collaborative learning should be used to deepen students' knowledge and understanding of a variety of learning content and enhance their comprehensive understanding of university classroom learning. As a well-rounded and focused educational component, this is the key to improving the effectiveness and efficiency of student learning, and teachers should have a good understanding of classroom instruction, make full use of classroom practices, and play a significant role in assessing student group learning ${ }^{[5]}$. By positively evaluating students' learning content and knowledge, their performance in integrating and learning expertise and promoting the development of innovative thinking is enhanced.

(4) Post-course consolidation to enhance learning. After the lesson, the teacher prepares students for homework at both the practical and theoretical levels, enabling them to consolidate and review their results and to describe the educational content of the course in full. And through regular practical training activities, students are encouraged to engage in teaching and practical activities according to their future career paths, providing a solid foundation for learning and practical exercises at the same time.

\section{Conclusion}

Overall, this paper discusses the application and practice of the flipped classroom in the current university curriculum. Although the pedagogical approach it uses differs more clearly from traditional methods, its ultimate core goal remains to guide students to become better. Therefore, teaching methods are not absolute opposites but can take advantage of the differences in different teaching methods to learn from and complement each other. In this paper, we only look at the educational practices and development models suitable for the Chinese education sector, intending to promote the steady development of the flipped classroom in education.

\section{References}

[1] Zhang ZH. The innovative application path of "online education + flipped classroom" in the ideological and political education of colleges and universities[J]. China Rural Education, 2020(17): 7-8.

[2] Wang Y, Zhang YJ. Research on the application of flipped classroom based on micro-classroom in college physical education curriculum[J]. Chinese Journal of Multimedia and Network Teaching (First Issue), 2020(06): 32-33.

[3] Chen MY. The implementation of a flipped classroom in teacher education courses in colleges and universities[J]. Journal of Hubei Open Vocational College, 2020, 33(07): 153-154+157.

[4] Liu GQ. Analysis of the use of flipped classroom in higher education courses[J]. Comparative Research on Cultural Innovation, 2020, 4(04): 145-146+173.

[5] Wu Y. Research on the flipped classroom teaching model in universities[J]. China Management Informatization, 2019, 22(24): 